\title{
A Study on Clearance Effects on Dynamic Responses of Robot Manipulator
}

\author{
Tianxi LIU*, Zhengfeng BAI** \\ *Department of Astronautics Engineering, Harbin Institute of Technology, Harbin, 150001, P.R. China \\ **Department of Mechanical Engineering, Harbin Institute of Technology, Weihai, 264209, P.R. China, \\ E-mail: baizhengfeng@126.com (Corresponding author) \\ crossref http://dx.doi.org/10.5755/j02.mech.26580
}

\section{Introduction}

In general, the clearances in joints are always neglected in dynamics modeling and analysis of mechanisms, such as robot manipulator systems. However, clearances are existed in joints of real mechanisms due to assemblage, manufacturing errors and wear [1-8]. Further, clearances will induce undesired effect on performances of real mechanism systems since of vibration caused by contact and impact in joints [9-13]

Robot manipulators are widely used in dangerous jobs, such as manipulators designed and used in spacecraft. Usually, the researchers and engineers focus on dynamics modeling and control of robot manipulators considering flexible bodies, control strategy and other topics [14-19]. However, in those studies, clearances in joints were not considered in the dynamic models of robot manipulators, which will lead to an inaccurate result of the real mechanism. Therefore, many works have been carried out to investigate the effects of clearances on various kinds of mechanism [2024].

Erkaya et al. [25, 26] presented a study on decreasing the deviations arising from a clearance joint in planar linkage mechanisms by neural network-genetic algorithm procedure. Muvengei et al. [27] investigated the dynamics and motion modes of a slider-crank mechanism with two planar revolute clearance joints. Stoenescu and Marghitu [28] investigated the dynamic responses of a planar, rigidlink mechanism with a sliding joint clearance and the response of the system with clearance was chaotic at relatively high crank speeds and low values of the coefficient of restitution. Wang et al. [29] presented a non-penetration approach of frictional contact analysis for modeling revolute clearance joints of planar rigid multibody systems. Zhang [30] proposed a method to minimize the influence of revolute joint clearance of redundantly actuated mechanism. A planar 3DOF redundantly actuated 4-RRR mechanism with 8 clearance joints is applied as an illustration. Salahshoor et al. [31] studied the effect of joint stiffness on the vibration behavior of a typical slider-crank mechanism with a flexible component and joint clearances. Wang et al. [32] studied the dynamic responses of planar multibody systems with dry revolute clearance joint considering the radial clearance via numerical and experimental approaches. Tan et al. [33] investigated the effects of friction on dynamic behavior of a planar crank-slider mechanism considering revolute joint with radial clearance using the LuGre friction model. Chen et al [34] analyzed the effect of multiple clearances and different friction models on the dynamic behavior of a planar
multi-DOF mechanism. The 2 DOFs nine-bar planar mechanism is used as the application example. Li et al [35] investigated the dynamic behavior of planar rigid-flexible coupling solar array system considering joint clearance numerically. A typical solar array model was used as application example. Wang et al. [36] studied the dynamic model of 4SPS/PS parallel mechanism with a flexible actuated rod and clearance spherical joint. Pi and Zhang [37] presented a study of dynamic analysis of the classical planar slidercrank mechanism with multiple revolute clearance joints. A general multiple patch based revolute clearance joint model was proposed. Amiri et al [38] proposed a control scheme to restrain the clearance and maintain a more stable behavior of planar mechanisms. The approach was based on using tuned mass damper to reduce the effects of clearances in mechanisms for passive control purpose. Zhan et al. [39] presented a unified motion reliability analysis method for general planar parallel manipulators with interval clearance variables of revolute and prismatic joints. Two typical types of PPMs, 3RRR PPM and 3PRR PPM, are analyzed as examples. Guo et al. [40] presented a dynamic model to investigate the position secondary motion considering all associated joint clearances. However, these works were limited to the linkage mechanism, such as slider-crank mechanism and son on. Few studies have been focused on robot manipulator system with clearance joints.

Therefore, this paper is focus on investigation of clearance effects on dynamic responses of robot manipulator system with clearance joint and is organized as follows. In section 2, the mathematical model of clearance joint is developed. Corresponding contact force along normal and tangential direction resulted from clearance joint is archived in section 3, with the employment of a hybrid nonlinear contact force model and a modified Coulomb friction model, respectively. Subsequently dynamical system equations taking clearance into account are derived in section 4 and a numerical application in terms of robot manipulator system is performed in section 5 . Section 6 conclude the presented work.

\section{Definition of clearance}

Usually, a clearance joint included in a planar robot manipulator system is revolute joint as depicted in Figure 1. The radial clearance is defined by the difference in radius between bearing and journal, which is defined by Eq. (1). Dynamics of the clearance joint is controlled by contact and impact forces resulted from the contact and impact behavior between the journal and bearing. Due to the contact and im- 
pact in clearance joint, three motion modes of journal motion appeared inside the bearing for mechanism with revolute clearance joints, which are categorized as the sustained contact mode, the free flight mode, and the impact mode, as depicted in Fig. 1b.

$$
c=R_{B}-R_{J},
$$

where: $R_{B}$ and $R_{J}$ are the radius of the bearing and journal.
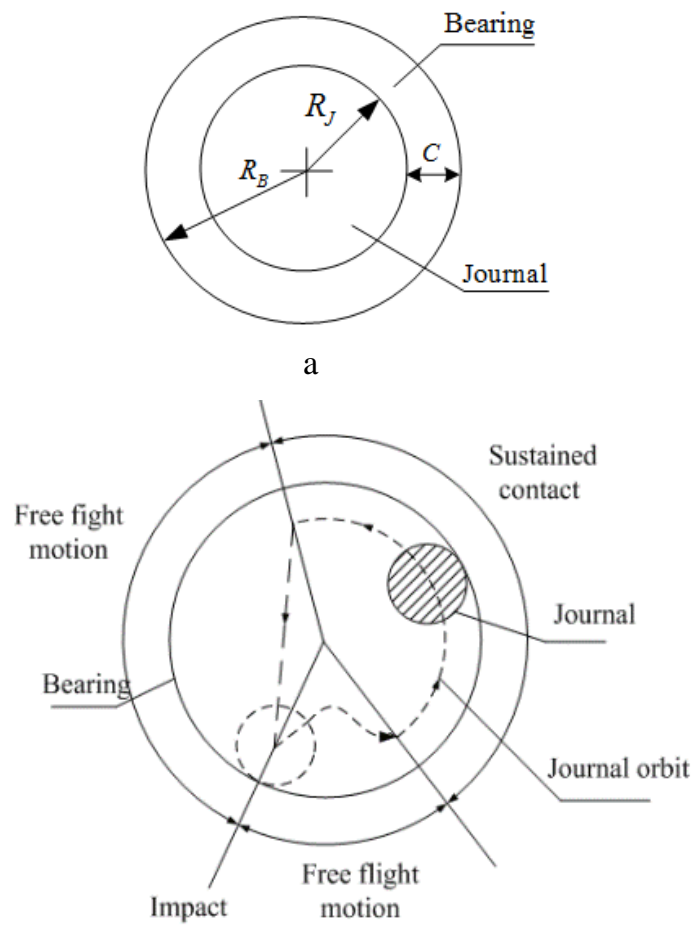

b

Fig. 1 The sketch map of revolute clearance joint: a) revolute joint with clearance, b) journal motion inside the bearing boundaries

\section{Contact force models}

\subsection{Normal contact force model}

When dynamic analysis of mechanisms with clearance joint are performed, special attention must be payed to the numerical expression of the contact force mode [41-47]. In this paper, a hybrid nonlinear contact force model [45] is adopted to describe the normal contact of clearance joint. This contact force model is a novel hybrid model mixing the Lankarani-Nikravesh model and the improved Winkler elastic foundation model.

The Lankarani-Nikravesh contact force model is shown in Eq. (2) [46]:

$$
F_{n}=K \delta^{n}+\frac{3 K\left(1-c_{e}^{2}\right) \delta^{n}}{4 \dot{\delta}^{(-)}} \dot{\delta},
$$

where: $K$ is the contact stiffness coefficient; $\delta$ is the deformation; $\dot{\delta}$ is the relative deformation velocity; $c_{e}$ is coefficient of restitution and $\dot{\delta}^{(-)}$is initial relative velocity of the impact point.

Liu et al. [47] presented a relationship between load and displacement for cylindrical joint with clearance as expressed in Eq. (3):

$$
F_{N}=\frac{1}{2} \pi \delta E^{*}\left(\delta /\left(2\left(R_{i}-R_{j}+\delta\right)\right)\right)^{\frac{1}{2}}
$$

where: $F_{N}$ is the normal load; $R_{i}$ and $R_{j}$ are radii of the joint elements; $E^{*}$ is the compound elastic modulus and represented as Eq. (4):

$$
\frac{1}{E^{*}}=\frac{1-v_{i}^{2}}{E_{i}}+\frac{1-v_{j}^{2}}{E_{j}},
$$

where: $v$ and $E$ are Poisson ratio and Young modulus, respectively.

The Lankarani-Nikravesh contact force model includes energy dissipation but it is applicable only for big joint clearance contact with high coefficient of restitution. And Liu's contact force model is suitable for both big clearance and small clearance and presented better precision [47]. However, it does not include energy dissipation.

Further, a hybrid model combined the LankaraniNikravesh model with the improved elastic foundation model is presented for revolute joint with clearance, with the following expression [45].

$$
F_{n}=K_{n} \delta^{n}+D_{m o d} \dot{\delta},
$$

where: $K_{n}$ is the nonlinear contact stiffness coefficient and $D_{\text {mod }}$ is the modified damping coefficient.

Based on the contact theory, $K_{n}$ is found from Eq. (3) and expressed as Eq. (6):

$$
K_{n}=\frac{1}{8} \pi E^{*} \sqrt{\frac{2 \delta\left(3\left(R_{B}-R_{J}\right)+2 \delta\right)^{2}}{\left(R_{B}-R_{J}+\delta\right)^{3}}} .
$$

It can be found that the nonlinear stiffness coefficient is variable during the contact process. Coefficient $D_{\text {mod }}$ in Eq. (5) is expressed as Eq. (7) [43]:

$$
D_{m o d}=\frac{3 K_{n}\left(1-c_{e}^{2}\right) e^{2\left(1-c_{e}\right)} \delta^{n}}{4 \dot{\delta}^{(-)}}
$$

where: $D_{\text {mod }}$ is available for both large and small coefficient of restitution; $c_{e}$ is coefficient of restitution.

Employment of the hybrid nonlinear contact model in the dynamic analysis procedure of planar mechanism with revolute clearance joint present a well agreement compared with experimental results. It is obviously that the hybrid nonlinear contact model is a novel normal contact force model for revolute joint with clearance [45]. Thus, in this work, we investigate the clearance effects on robot manipulator using this novel normal contact force model.

\subsection{Friction force model of revolute joint with clearance}

For a clearance joint, the tangential contact commonly is represented with friction force. In this work, a modified Coulomb friction model with dynamic friction coefficient is used for tangential contact of clearance joint, 
which can avoid numerical difficulties $[43,45]$. The expression of the modified Coulomb friction mode is shown as Eq. (8):

$$
F_{t}=-\mu\left(v_{t}\right) F_{n}\left(v_{t} /\left|v_{t}\right|\right)
$$

where the dynamic friction coefficient $\mu\left(v_{t}\right)$ is a function of tangential velocity and it can be calculated using Eq. (9). The function curve of dynamic friction coefficient is shown as Fig. 2.

$$
\mu\left(v_{t}\right)=\left\{\begin{array}{cl}
-\mu_{d} \operatorname{sign}\left(v_{t}\right) & \text { for }\left|v_{t}\right|>v_{d} \\
-\left\{\mu_{d}+\left(\mu_{s}-\mu_{d}\right)\left(\frac{\left|v_{t}\right|-v_{s}}{v_{d}-v_{s}}\right)^{2}\left[3-2\left(\frac{\left|v_{t}\right|-v_{s}}{v_{d}-v_{s}}\right)\right]\right\} \operatorname{sign}\left(v_{t}\right) & \text { for } \quad v_{s} \leq\left|v_{t}\right| \leq v_{d}, \\
\mu_{s}-2 \mu_{s}\left(\frac{v_{t}+v_{s}}{2 v_{s}}\right)^{2}\left(3-\frac{v_{t}+v_{s}}{v_{s}}\right) & \text { for }\left|v_{t}\right|<v_{s}
\end{array}\right.
$$

where: $v_{t}$ is relative sliding velocity; $v_{s}$ is critical velocity of static friction; $v_{d}$ is critical velocity of the maximum dynamic friction; $\mu_{d}$ and $\mu_{s}$ are dynamic and static friction coefficient, respectively.

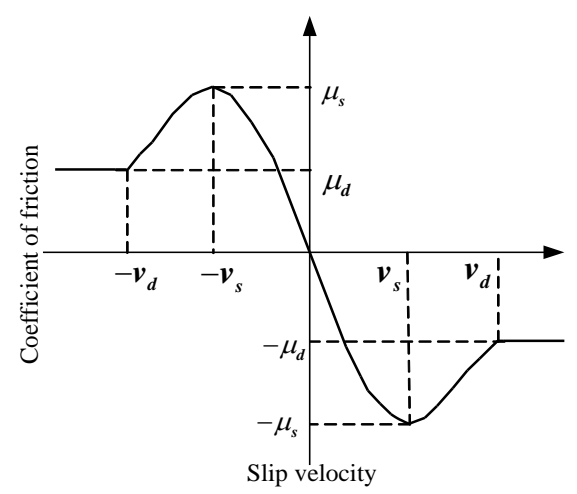

Fig. 2Coefficient of friction vs. slip velocity

\section{Dynamics equations of mechanism with clearance}

In general, clearance in joint leads to two different motion phases of bodies connected with the clearance joint. One is the bodies move free in the clearance; the other is the bodies contact and interacts. Therefore, the motion of mechanism with clearance is considered as free motion state and contact state. Thereby, the dynamics equations of the mechanisms with clearance are obtained using Lagrange multiplier method and expressed as followings. expressed as:

In the free motion phase, the dynamic equation is

$$
\begin{aligned}
& \mathbf{M} \ddot{\boldsymbol{q}}+\mathbf{C} \dot{\mathbf{q}}+\mathbf{K q}+\boldsymbol{\Phi}_{q}^{T} \boldsymbol{\lambda}=\mathbf{F} \\
& \Phi(\mathbf{q}, t)=\mathbf{0}
\end{aligned}
$$

In the contact phase, the bodies are contact and interact. Therefore, the contact forces are included in the Eq. (10) and the dynamic equations are presented as:

$$
\begin{aligned}
& \mathbf{M} \ddot{\boldsymbol{q}}+\mathbf{C} \dot{\mathbf{q}}+\mathbf{K q}+\boldsymbol{\Phi}_{\mathbf{q}}^{T} \boldsymbol{\lambda}=\mathbf{F}+\mathbf{F}_{c}, \\
& \boldsymbol{\Phi}(\mathbf{q}, t)=\mathbf{0}
\end{aligned}
$$

where: $\mathbf{F}_{c}$ is the contact force, which contains both normal contact force; $F_{n}$, as shown in Eq. (5), and tangential friction force; $F_{t}$, as shown in Eq. (8); $\mathbf{q}$ denotes the generalized coordinate column matrix; $\mathbf{M}, \mathbf{C}$ and $\mathbf{K}$ are the generalized mass matrix, generalized damp matrix and generalized stiffness matrix respectively; $\Phi_{\mathbf{q}}$ is the Jacobin matrix of constraint equation; $\mathbf{F}$ is the generalized force matrix; $\lambda$ is the Lagrange multiplier column matrix.

\section{Numerical examples}

In this section, the dynamics analysis of a planar robot manipulator system on spacecraft is used as the application example to investigate the effects of clearance on dynamic performances of the manipulator system. The dynamic simulation is performed suing the MSC.ADAMS, a mechanical system simulation software. The robot manipulator system on spacecraft is usually used to capture and operate target space, as shown in Fig. 3, which consists of two manipulator arms. It's assumed that the clearance joints between arm 1 and arm 2 is imperfect with clearance, while the ideal joint is between arm1 and spacecraft without of clearance. The initial configuration of arm 1 and arm 2 are horizontal. The initial position and velocity of each arm are zero. The mass and inertia properties of the manipulator system on spacecraft are presented in Table 1. And Table 2 exhibits the dynamic simulation parameters used for the system.

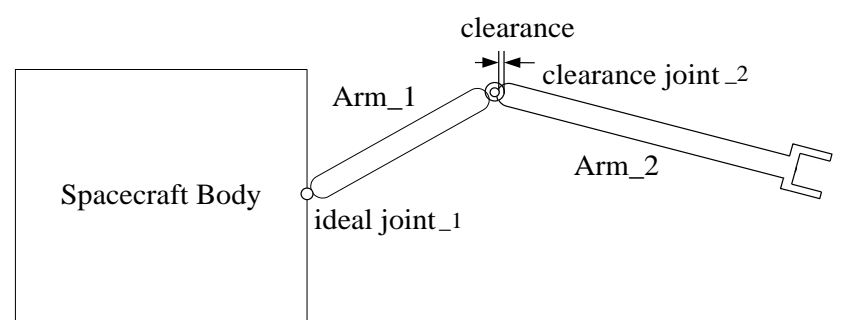

Fig. 3 Robot manipulator system with clearance on spacecraft (the joint clearance zoom-in)

First, dynamic simulation for robot manipulator system is performed with consideration of joint without clearance and imperfect joint with $0.4 \mathrm{~mm}$ clearance. The dynamic simulation results obtained from ideal system without clearance are compared with that of real system with clearance joint. Figs. 4, 5 and 6 are angular displacement, velocity and acceleration of arm 2 of the robot manipulator system, respectively. 
Table 1

Mass and inertia properties

\begin{tabular}{|l|l|l|l|}
\hline & Arm_1 & Arm_2 & Spacecraft body \\
\hline Length, $\mathrm{m}$ & 1.0 & 1.6 & - \\
\hline Mass, $\mathrm{kg}$ & 2.513 & 4.021 & 1200 \\
\hline Inertia, $\mathrm{kg} \cdot \mathrm{m}^{2}$ & 0.210 & 0.859 & 200 \\
\hline
\end{tabular}

Table 2

Parameters used in dynamic simulation of robot manipulators on spacecraft

\begin{tabular}{|l|l|}
\hline Drive Torque $T_{1}, \mathrm{Nm}$ & $1.2 \times \sin (2 \pi t)$ \\
\hline Drive Torque $T_{2}, \mathrm{Nm}$ & $0.5 \times \sin (2 \pi t)$ \\
\hline Dynamic friction coefficient & 0.1 \\
\hline Restitution coefficient & 0.9 \\
\hline
\end{tabular}

Fig. 4 shows that the angular displacement of manipulator arm is approximate for robot manipulator considering ideal joint and clearance joint. Obviously, the angular displacement of robot manipulator is affected by clearance lightly. Fig. 5 shows that the angular velocity of manipulator arm is vibration with high peaks and clearance has an obvious influence on motion velocity of manipulator system. It's similarly in Fig. 6 that the motion acceleration of manipulator system represents high peaks caused by contact and impact forces caused in clearance joint. When considering clearance, the motion acceleration is obvious vibrated with higher peaks of value, which will lead to the decrease of dynamic performance as well as motion stability of the robot manipulator system.

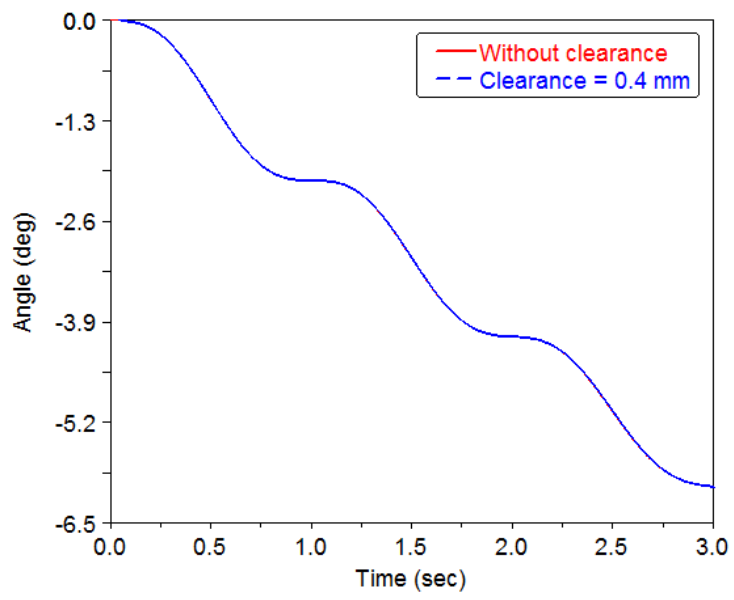

Fig. 4 Angular displacement

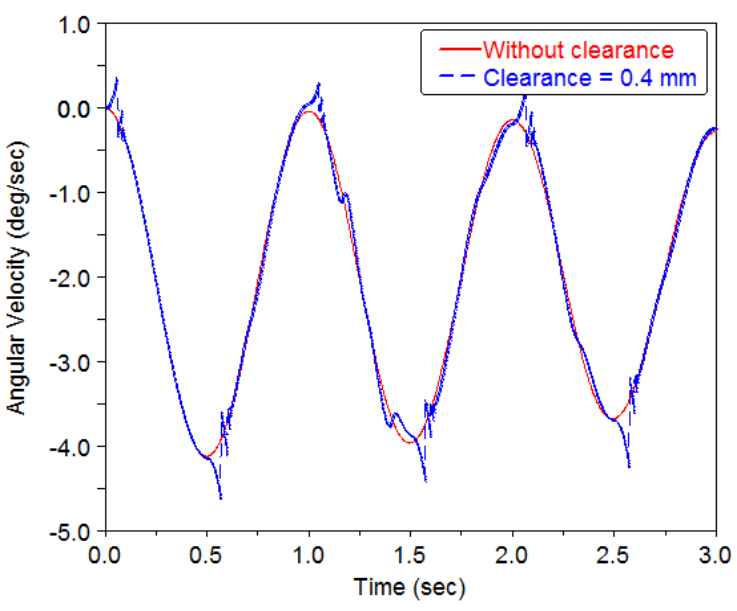

Fig. 5 Angular velocity

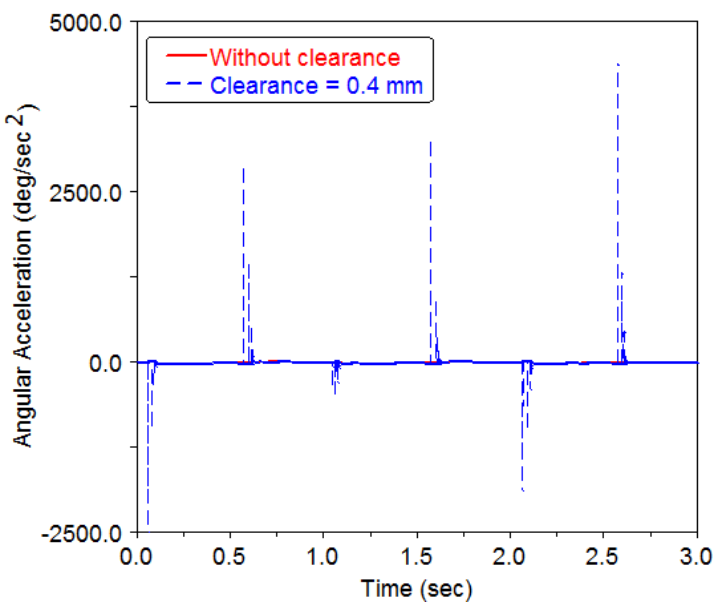

Fig. 6 Angular acceleration

Fig. 7 shows the contact force components in ideal joint and clearance joint. From Figure 7, it can be found that clearance induces impulse type contact and impact forces, which presents higher peaks than ideal case and decease the performances of the manipulator system.
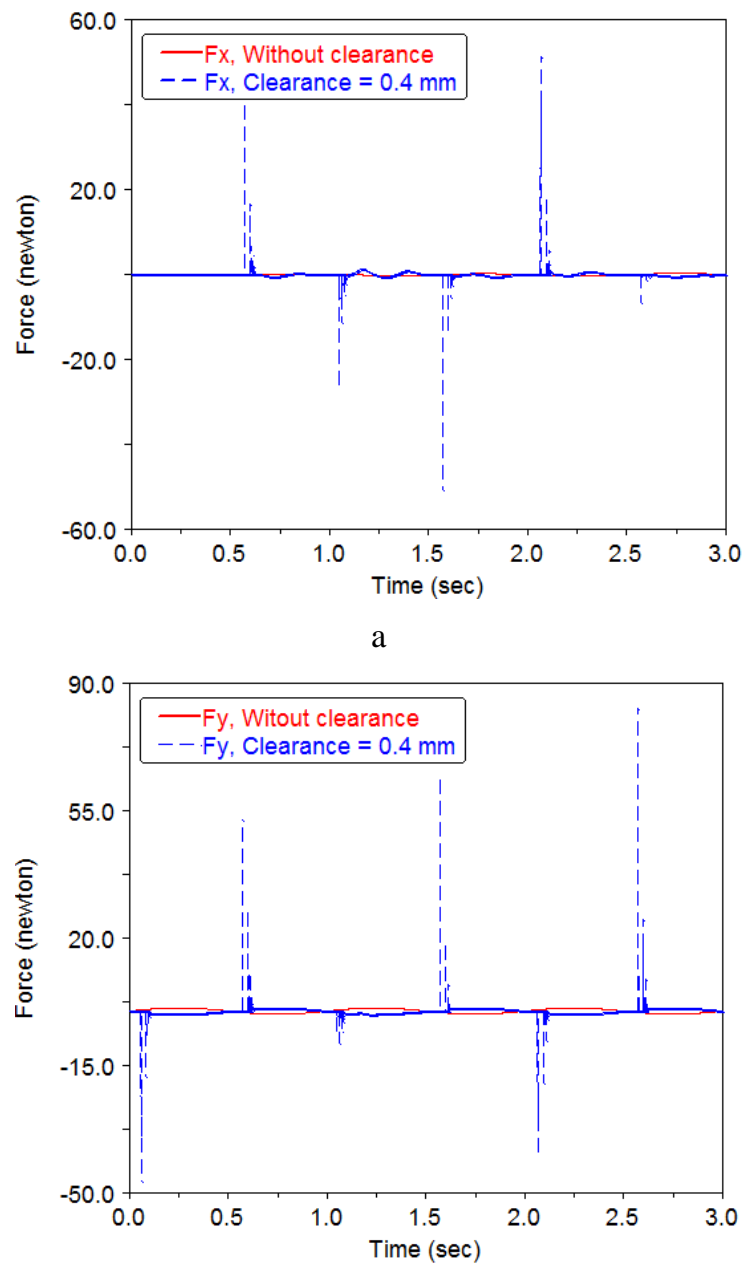

b

Fig. 7 Force component of clearance joint: a) X direction,

b) Y direction

As one of the most important factors, clearance size affects the dynamic response of robot manipulator system. Furthermore, the effects of clearance size on the dynamics responses of the real robot manipulator system are investigated. Four case studies for different clearance sizes 
are presented and discussed. The clearance sizes here are valued as $0.05 \mathrm{~mm}, 0.1 \mathrm{~mm}, 0.2 \mathrm{~mm}$ and $0.4 \mathrm{~mm}$ for each case, respectively. The simulation results of each case are presented as follows.

The trajectories of the journal centre relative to the bearing centre for each case study are presented in Fig. 8, where the solid-line and dot-line designate the radial clearance circle and the journal centre trajectory inside the bearing, respectively. It is note that in the initial configuration of dynamic simulation, coincidence of the journal centre with the bearing centre is hold. Observing Fig. 8, it's clearly that motion trajectory between journal and bearing manifest various types. Starting with the robot manipulator operation, the journal moves freely, and contact and impact happened when it moves to the bearing boundary. It indicates that the motion of manipulator with clearance joint has various modes due to contact in clearance joint, which are free flight motion, impact and sustained contact. However, the journal orbits are obviously different with different clearance sizes.

Figs. 9 and 10 are angular velocity and acceleration of arm 2 when considering different clearance sizes, respectively. The results clearly show that the dynamic responses
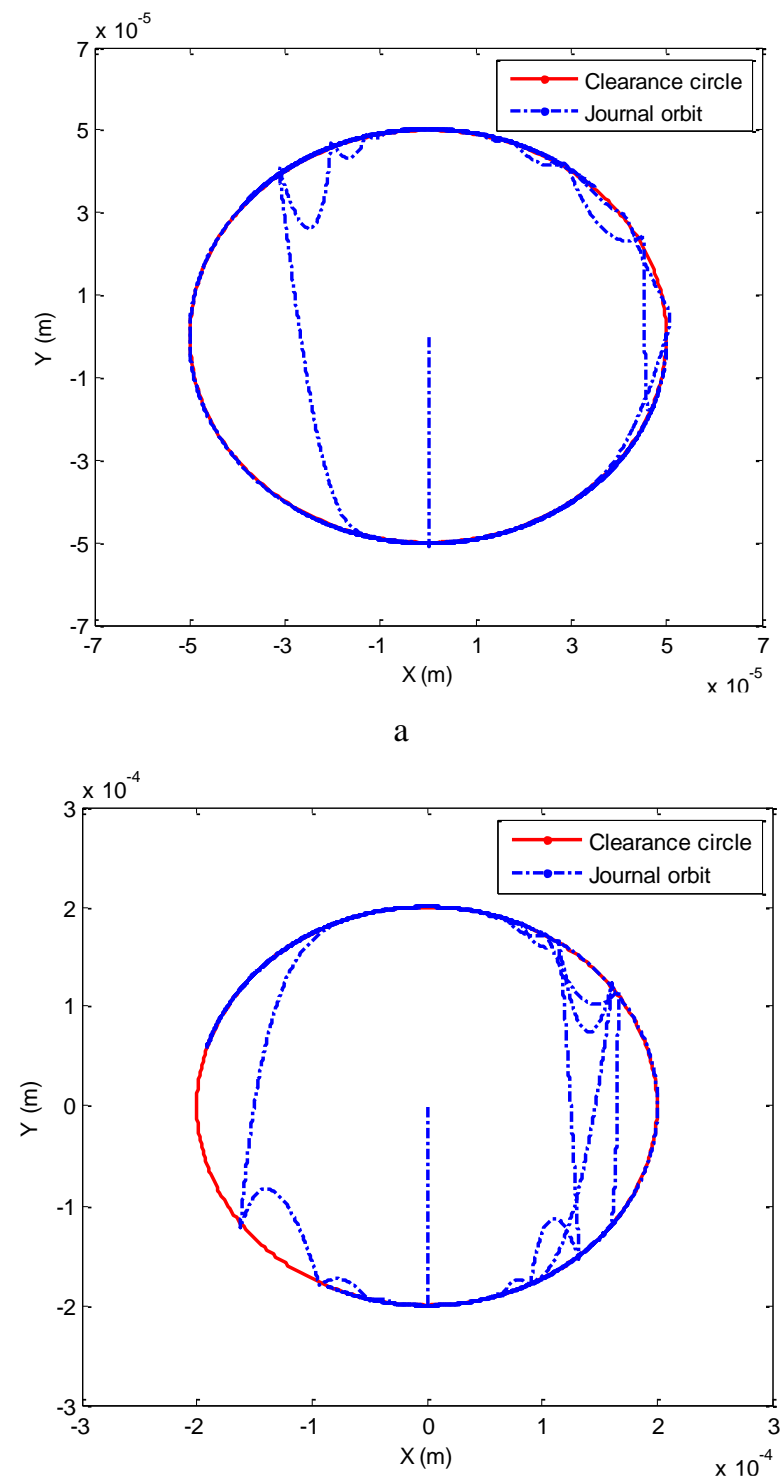

of manipulator arm are changed obviously for different clearance sizes. With the size of clearance increased, vibration and higher peaks of the system's responses displayed more significantly.

Further, the translational acceleration of the tip of manipulator arm are presented in Fig. 11. It also shows that bigger clearance size will induce more intense vibration and higher peaks of the manipulator arm tip. Therefore, bigger size of clearance will increase the amplitude of the manipulator arm and cause the dynamics performance of manipulator arm worse.

In addition, the simulation results of this work are compared to other publications of multibody mechanical system with joint clearance, such as planar linkage mechanism, which concluded that clearance had significant influence on the dynamics of mechanisms [1, 5, 23, 25]. Consequently, the validity of presented work is confirmed by the other published data. In conclusion, during the dynamic analysis of robot manipulator system, modelling of model of contact and impact forces in clearance joints must be considered due to its significant effect on dynamic performances

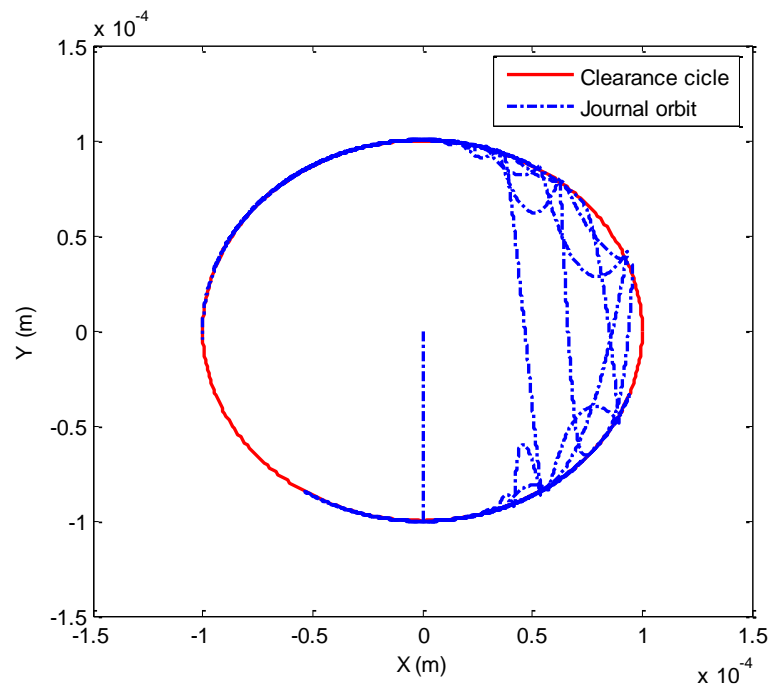

$\mathrm{b}$

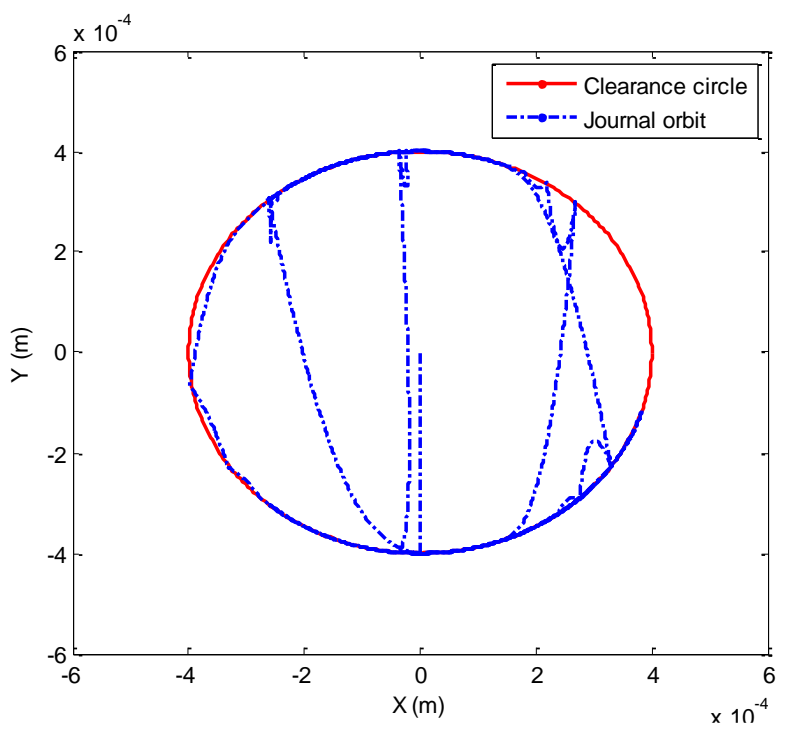

d

Fig. 8 Orbit of journal center inside bearing for different clearance sizes a) $c=0.05 \mathrm{~mm}$; b) $c=0.1 \mathrm{~mm}$; $) c=0.2 \mathrm{~mm}$; d) $c=0.4 \mathrm{~mm}$ 


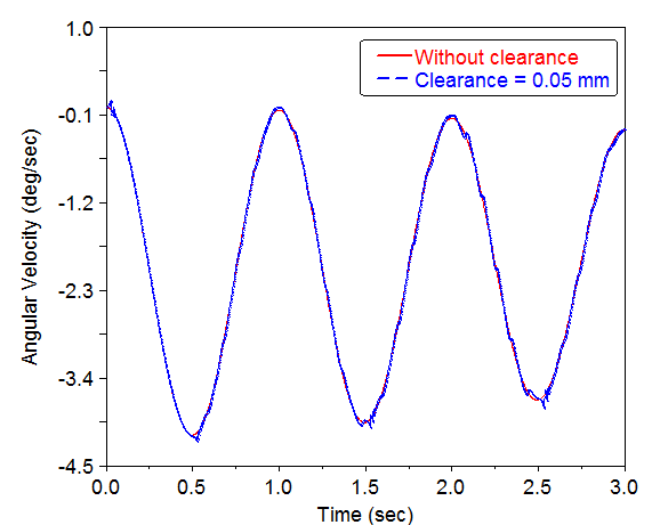

a

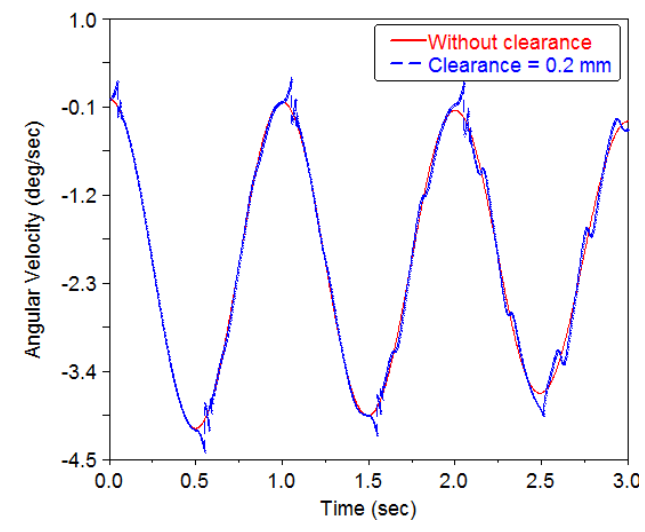

c

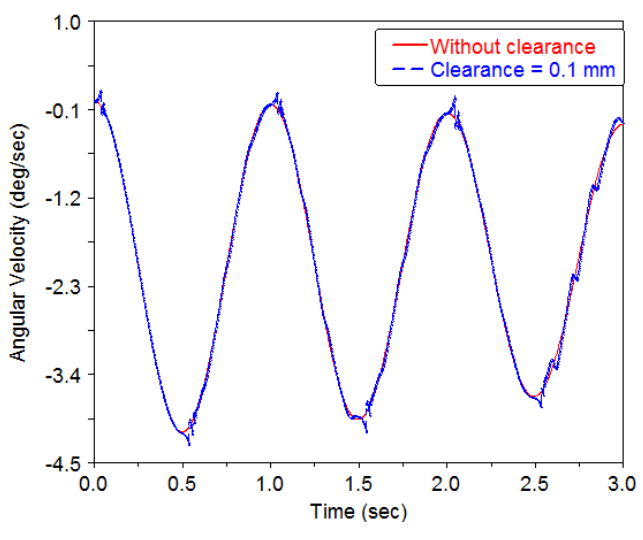

b

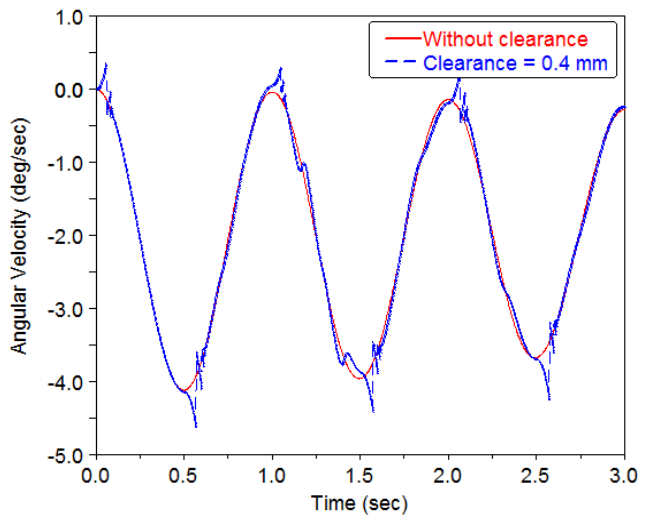

d

Fig. 9 Angular velocity of robot manipulator for different clearance sizes: a) $c=0.05 \mathrm{~mm}$; b) $c=0.1 \mathrm{~mm}$; c) $c=0.2 \mathrm{~mm}$; d) $c=0.4 \mathrm{~mm}$
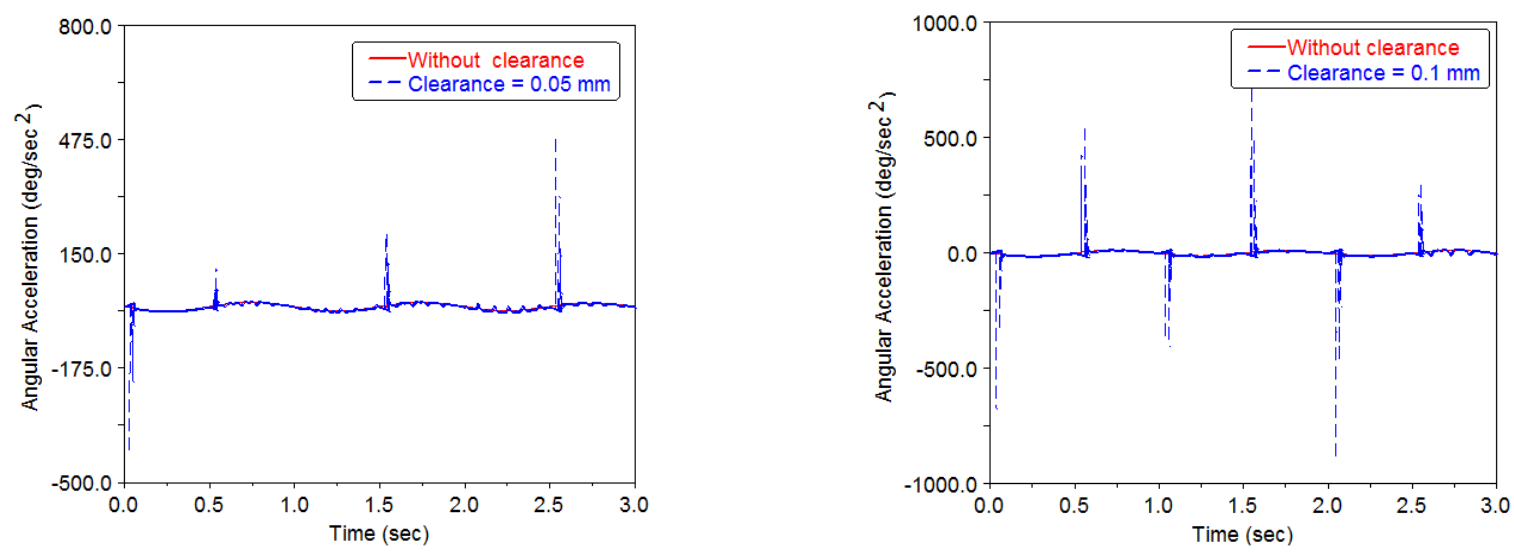

a

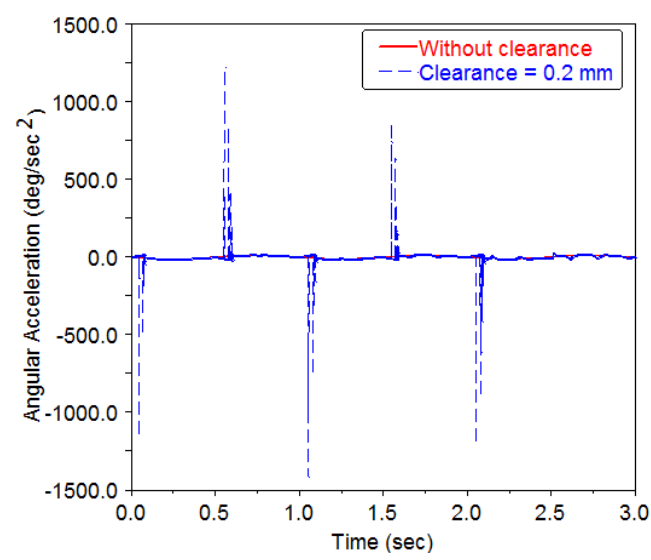

c

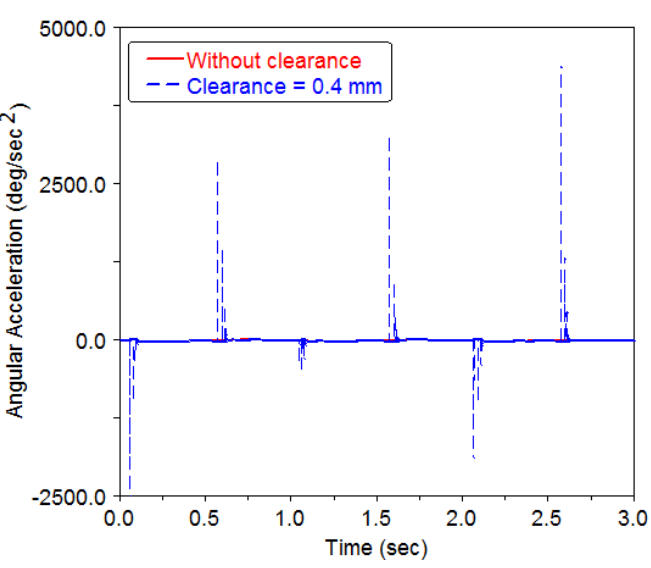

$\mathrm{d}$

Fig. 10 Angular acceleration of robot manipulator for different clearance sizes: a) $c=0.05 \mathrm{~mm}$; b) $c=0.1 \mathrm{~mm}$; $) c=0$. $2 \mathrm{~mm}$; d) $c=0.4 \mathrm{~mm}$ 


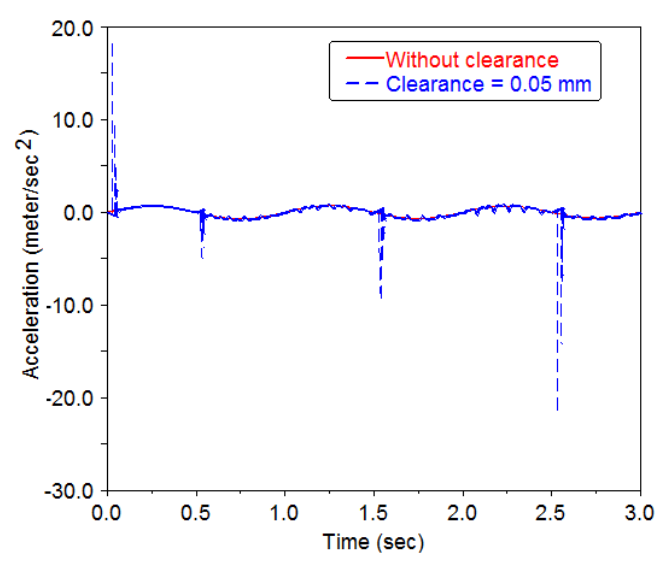

a

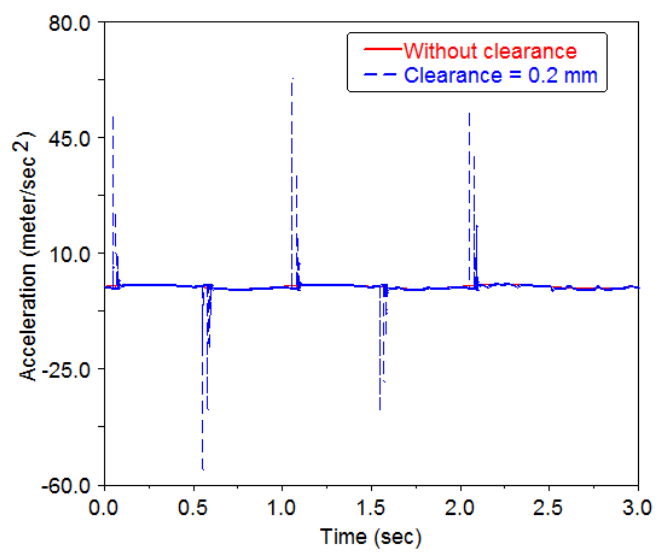

c

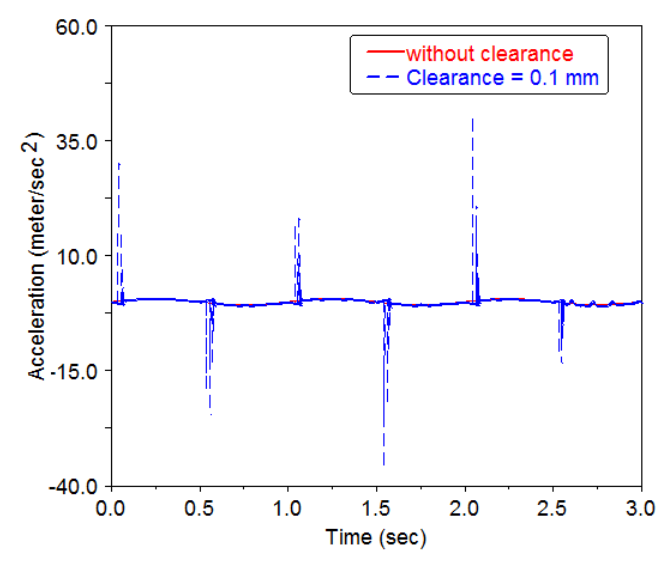

b

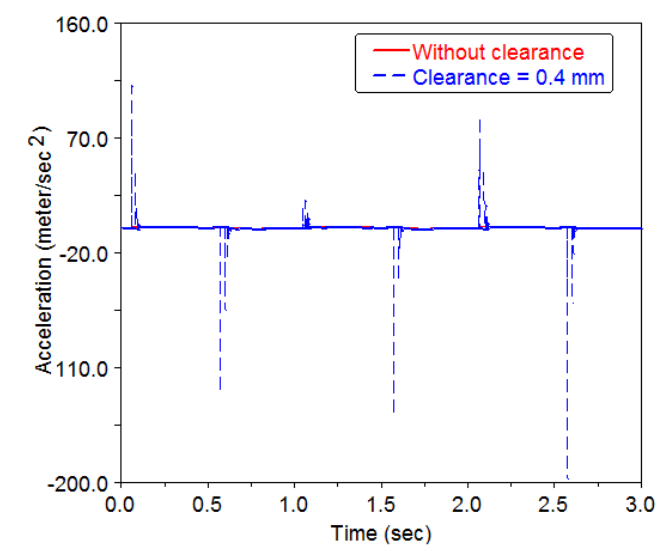

d

Fig. 11 Translational acceleration in Y-direction of the manipulator with different clearance sizes: a) $c=0.05 \mathrm{~mm}$; b) $c=$ $=0.1 \mathrm{~mm}$; $) c=0.2 \mathrm{~mm}$; d) $c=0.4 \mathrm{~mm}$

\section{Conclusions}

The effects of clearance on a robot manipulator system are investigated numerically. The contact dynamical behavior in clearance joint is surveyed, in which, the normal contact is modeled using a hybrid nonlinear contact force model and the tangential contact is modeled using a modified Coulomb friction model. A planar robot manipulator system with a revolute clearance joint on a spacecraft is applied as the numerical example to investigate the effects of clearance on dynamics responses of mechanism. Four case studies for different clearance sizes are implemented to investigate and discuss the effects of joint clearance.

It can be concluded that in contrast with the slight effects on displacement, the clearance affects significantly velocity and acceleration of robot manipulator system. In detail, clearance affects the motion velocity of real manipulator system for reason of vibration around that of ideal manipulator system without clearance. Moreover, clearance affects the acceleration of robot manipulator more profoundly, which is owe to the contact and impact forces caused by clearance joint. It indicates that the acceleration of manipulator system presents high peaks and the clearance induces impulse type contact force in joint, which will increase the vibration and noise levels and reduce system reliability, stability as well as system component's life. Additionally, bigger size of clearance will lead to more significant effects on robot manipulator system, which is represented by higher vibration amplitudes.

The presented work is devoted to predict the effects of clearance on robot manipulator system preferably and contributes to provide the foundation of precision analysis, robust control system design to robot manipulator system. In this study, the robot manipulator system with clearance on spacecraft is modeled as planar mechanical system and only one joint is considered as imperfect. The dynamics analysis of robot manipulator system will be much closer to the real robotic system with several imperfect joints, which will be the next research. Our future work will be also focused on more complex robotic system with more clearance joints.

\section{Acknowledgment}

This work is supported by the National Natural Science Foundation of China (Grant Nos. 51775128, 51305093).

\section{References}

1. Varedi, S. M.; Daniali, H. M.; Dardel, M. 2015. Dynamic synthesis of a planar slider-crank mechanism with clearances, Nonlinear Dynamics 79: 1587-1600. https//doi.org/10.1007/s11071-014-1762-x.

2. Wang, X.; Liu, G.; Ma, S.; Tong. R. 2018. Study on dynamic responses of planar multibody systems with dry revolute clearance joint: numerical and experimental approaches, J. Sound Vib. 438: 116-138. https//doi.org/10.1016/j.jsv.2018.08.052.

3. Tan, H.; Hu, Y.; Li. L. 2019. Effect of friction on the dynamic analysis of slider-crank mechanism with clearance joint, Int. J. Mech. Sci. 115: 20-40. 
https//doi.org/ 10.1016/j.ijnonlinmec.2019.04.009.

4. Zhao, Q.; Guo, J.; Hong, J.; Liu, Z. 2019. Analysis of angular errors of the planar multi-closed-loop deployable mechanism with link deviations and revolute joint clearances, Aerosp. Sci. Tech. 87:25-36 https://doi.org/10.1016/j.ast.2019.02.013.

5. Erkaya, S.; Uzmay, I. 2009. Investigation on effect of joint clearance on dynamics of four-bar mechanism, Nonlinear Dynamics 58: 179-198. https//doi.org/10.1007/s11071-009-9470-7.

6. Daniel, G. B.; Cavalca, K. L. 2011. Analysis of the dynamics of a slider-crank mechanism with hydrodynamic lubrication in the connecting rod-slider joint clearance, Mech. Mach. Theory 46:1434-1452. https://doi.org/10.1016/j.mechmachtheory.2011.05.007.

7. Zhao, B.; Dai, X. D.; Zhang, Z. N. 2014. Numerical study of parametric effects on joint wear in the flexible multibody systems with different flexibilities and clearance sizes, Journal of Engineering Tribology 228(8): 819835. https//doi.org/ 10.1177/1350650114531745.

8. Mukras, S.; Kim, N. H.; Mauntler, N. A.; Schmitz, T. L.; Sawyer, W. G. 2010. Analysis of planar multibody systems with revolute joint wear, Wear 268:643-652. https://doi.org/10.1016/j.wear.2009.10.014.

9. Olyaei, A. A.; Ghazavi, M. R. 2012. Stabilizing slidercrank mechanism with clearance joints, Mechanism and Machine Theory 53: 17-29. https//doi.org/10.1016/j.mechmachtheory.2012.02.006.

10. Flores, P. 2009. Modeling and simulation of wear in revolute clearance joints in multibody systems, Mech. Mach. Theory 44:1211-1222. https://doi.org/10.1016/j.mechmachtheory.2008.08.003.

11. Li, J.; Huang, H.; Yan, S.; Yang. Y. 2017. Kinematic accuracy and dynamic performance of a simple planar space deployable mechanism with joint clearance considering parameter uncertainty, Acta Astronaut. 136: 34-45. https//doi.org/10.1016/j.actaastro.2017.02.027.

12. Brogliato, B. 2018. Feedback control of multibody systems with joint clearance and dynamic backlash: a tutorial, Multibody Syst Dyn. 42:283-315 https://doi.org/10.1007/s11044-017-9585-4.

13. Li, Y.; Wang, Z.; Wang, C.; Huang, W. 2017. Effects of torque spring, CCL and latch mechanism on dynamic response of planar solar arrays with multiple clearance joints, Acta Astronaut. 132:243-255. https://doi.org/10.1016/j.actaastro.2016.12.032.

14. Paredis, C. J. J.; Brown, H. B.; Khosla, P. K. 1997. A rapidly deployable manipulator system, Robotics and Autonomous Systems 21: 289-304. https//doi.org/10.1109/robot.1996.506907.

15. Subudhi, B.; Morris, A. S. 2002. Dynamic modelling; simulation and control of a manipulator with flexible links and joints, Robotics and Autonomous Systems 41: 257270.

https//doi.org/10.1016/s0921-8890(02)00295-6.

16. Wei, C.; Liu, T. X.; Zhao, Y. 2010. Grasping strategy in space robot capturing floating target, Chinese Journal of Aeronautics 23: 591-598.

https//doi.org/ 10.1016/s1000-9361(09)60259-4.

17. Reedman, M. C. 2003. Approaches for dynamic modeling of flexible manipulator systems, Control Theory and Applications 4(6): 401-411.

https//doi.org/10.1049/ip-cta:20030496.
18. Aoustin, Y.; Formalsky, A. 1999. On the feed forward torques and reference trajectory for flexible two-link arm, Multibody System Dynamics 3: 241-265.

https//doi.org/10.1023/A:1009875908235.

19. Xu, B.; Fujimoto K.; Hayakawa, Y. 2004. Control of two-link flexible manipulators via generalized canonical transformation, IEEE Conference on Robots, Automation and Mechatronics, Singapore 107-112. https//doi.org/10.1109/ramech.2004.1438900.

20. Sun, D.; Shi, Y.; Zhang. B. 2018. Robust optimization of constrained mechanical system with joint clearance and random parameters using multi-objective particle swarm optimization, Struct. Multidiscip. O. 58: 2073-2084. https//doi.org/10.1007/s00158-018-2021-4.

21. Li, Y.; Wang. C.; Huang. W. 2019. Rigid-flexible-thermal analysis of planar composite solar array with clearance joint considering torsional spring, latch mechanism and attitude controller, Nonlinear Dyn. 96: 2031-2053. https//doi.org/10.1007/s11071-019-04903-z.

22. Qian, M.; Qin, Z.; Yan, S.; Zhang. L. 2020. A comprehensive method for the contact detection of a translational clearance joint and dynamic response after its application in a crank-slider mechanism, Mech. Mach. Theory 145: 103717. https//doi.org/10.1016/j.mechmachtheory.2019.103717.

23. Flores, P. 2010. Parametric Study on the dynamic response of planar multibody systems with multiple clearance joints, Nonlinear Dynamics 61: 633-653. https//doi.org/10.1007/s11071-010-9676-8.

24. Bing, S.; Ye, J. 2008. Dynamic analysis of the reheatstop-valve mechanism with revolute clearance joint in consideration of thermal effect, Mech. Mach. Theory 43:1625-1638. https://doi.org/10.1016/j.mechmachtheory.2007.12.004.

25. Erkaya, S.; Uzmay, I. 2009. Determining link parameters using genetic algorithm in mechanisms with joint clearance, Mech. Mach. Theory 44: 222-234. https//doi.org/10.1016/j.mechmachtheory.2008.02.002.

26. Erkaya, S.; Uzmay, I. 2010. Experimental investigation of joint clearance effects on the dynamics of a slider-crank mechanism, Multibody Syst. Dyn. 24: 81-102. https//doi.org/10.1007/s11044-010-9192-0.

27. Muvengei, O.; Kihiu, J.; Ikua, B. 2013. Dynamic analysis of planar rigid-body mechanical systems with twoclearance revolute joints, Nonlinear Dyn. 73: 259-273. https//doi.org/10.1007/s11071-013-0782-2.

28. Stoenecu, E. D.; Marghitu, D. B. 2003. Dynamic analysis of a planar rigid-link mechanism with rotating slider joint and clearance, J. Sound Vib. 266:94-404. https://doi.org/10.1016/S0022-460X(03)00053-1.

29. Wang, G.; Qi, Z.; Wang. J. 2017. A differential approach for modeling revolute clearance joints in planar rigid multibody systems, Multibody Syst Dyn. 39: 311335. https//doi.org/10.1007/s11044-016-9552-5.

30. Zhang, X.; Zhang. X. 2017. Minimizing the influence of revolute joint clearance using the planar redundantly actuated mechanism, Robot. Com-Int Manuf. 46: 104-113. https//doi.org/10.1016/j.rcim.2017.01.006.

31. Salahshoor, E.; Ebrahimi, S.; Zhang. Y. 2018. Frequency analysis of a typical planar flexible multibody system with joint clearances, Mech. Mach. Theory. 126: 429456. https//doi.org/10.1016/j.mechmachtheory.2018.04.027. 
32. Wang, X.; Liu, G.; Ma, S.; Tong. R. 2019. Study on dynamic responses of planar multibody systems with dry revolute clearance joint: numerical and experimental approaches, J. Sound Vib., 438: 116-138. https//doi.org/10.1016/j.jsv.2018.08.052.

33. Tan, H.; Hu, Y.; Li. L. 2019. Effect of friction on the dynamic analysis of slider-crank mechanism with clearance joint, Int. J. Mech. Sci. 115: 20-40. https//doi.org/10.1016/j.ijnonlinmec.2019.04.009.

34. Chen, X.; Jiang, S.; Wang, S.; Deng. Y. 2019. Dynamics analysis of planar multi-DOF mechanism with multiple revolute clearances and chaos identification of revolute clearance joints, Multibody Syst. Dyn. 47: 317-345. https//doi.org/10.1007/s11044-018-09654-0.

35. Li, Y.; Wang, C.; Huang. W. 2019. Dynamics analysis of planar rigid-flexible coupling deployable solar array system with multiple revolute clearance joints, Mech. Syst. Signal Processing 117: 187-209. https//doi.org/10.1016/j.ymssp.2018.07.037.

36. Wang, G.; Wang. L. 2019. Dynamics investigation of spatial parallel mechanism considering rod flexibility and spherical joint clearance, Mech. Mach. Theory. 137: 83107. https//doi.org/10.1016/j.mechmachtheory.2019.03.017.

37. Pi, T.; Zhang. Y. 2019. Simulation of planar mechanisms with revolute clearance joints using the multipatch based isogeometric analysis, Comput. Methods Appl. Mech. Engrg. 343: 453-489. https//doi.org/10.1016/j.cma.2018.08.039.

38. Amiri, A.; Dardel, M.; Daniali. H.M. 2019. Effects of passive vibration absorbers on the mechanisms having clearance joints, Multibody Syst. Dyn. 47: 363-395. https//doi.org/10.1007/s11044-019-09684-2,

39. Zhan, Z.; Zhang, X.; Zhang, H.; Chen. G. 2019. Unified motion reliability analysis and comparison study of planar parallel manipulators with interval joint clearance variables, Mech. Mach. Theory. 138: 58-75. https//doi.org/10.1016/j.mechmachtheory.2019.03.041.

40. Guo, J.; Randall, R. B.; Borghesani, P.; Smith, W. A.; Haneef, M. D.; Peng, Z. 2020. A study on the effects of piston secondary motion in conjunction with clearance joints, Mech. Mach. Theory 149: 103824. https//doi.org/10.1016/j.mechmachtheory.2020.103824.

41. Tian, Q., Flores, P., Lankarani, H. M. 2018. A comprehensive survey of the analytical, numerical and experimental methodologies for dynamics of multibody mechanical systems with clearance or imperfect joints, Mechanism and Machine Theory 122:1-57. https://doi.org/10.1016/j.mechmachtheory.2017.12.002.

42. Flores, P; Ambrósio, J. 2004. Revolute joints with clearance in multibody systems, Computers and Structures 82 : 1359-1369. https//doi.org/10.1016/s0045-7949(04)00121-x.

43. Bai, Z. F.; Zhao, Y. 2012. Dynamic behaviour analysis of planar mechanical systems with clearance in revolute joints using a new hybrid contact force model, International Journal of Mechanical Sciences 54: 190-205. https//doi.org/10.1016/j.ijmecsci.2011.10.009.
44. Koshy, C. S.; Flores, P.; Lankarani, H. M. 2013. Study of the effect of contact force model on the dynamic response of mechanical systems with dry clearance joints computational and experimental approaches, Nonlinear Dynamics, 73: 325-338. https//doi.org/10.1007/s11071-013-0787-x.

45. Bai, Z. F.; Zhao, Y. 2013. A Hybrid contact model of revolute joint with clearance for mechanical systems, International Journal of Non-Linear Mechanics 48: 15-36. https//doi.org/10.1016/j.ijnonlinmec.2012.07.003.

46. Lankarani, H. M.; Nikravesh, P. E. 1990. A contact force model with hysteresis damping for impact analysis of multibody systems, ASME Journal of Mechanical Design 112: 369-376. https//doi.org/10.1115/1.2912617.

47. Liu, C. S.; Zhang, K.; Yang. R. 2007. The FEM analysis and approximate model for cylindrical joints with clearances, Mechanism and Machine Theory 42: 183-197. https//doi.org/10.1016/j.mechmachtheory.2006.02.006.

T. Liu, Z. Bai

\section{A STUDY ON CLEARANCE EFFECTS ON DYNAMIC RESPONSES OF ROBOT MANIPULATOR}

S u m m a r y

Clearances caused by assemblage, manufacturing errors and wear, affect inevitably the dynamic responses of mechanisms such as robot manipulator. In this study, the effects of clearance on a robot manipulator system are investigated numerically. The contact behavior along normal and tangential direction of clearance joint is described by a nonlinear contact force model and a modified Coulomb friction model respectively. Then, the dynamics equations of the robot manipulator system are established considering joint clearance. In order to investigate the effects of clearance on dynamic performances of practical mechanism, a planar robot manipulator system on a spacecraft system with a revolute clearance joint is used as the apply example. Four case studies for various clearance sizes are implemented to investigate and discuss the effects of joint clearance. The simulation results indicate that clearance joints have severe effects on the dynamic performances of mechanism system and the impact in clearance joints represented by contact force models must be considered in dynamics analysis and design of mechanism system. The simulation results in this work can predict the effects of clearance on robot manipulator system preferably and it is the basis of precision analysis, robust control system design of robot manipulator system.

Keywords: hybrid contact force model; dynamic responses; modified friction model; joint clearance; robot manipulator.

Received June 19, 2020

Accepted April 07, 2021 